Journal of Teacher Education for Sustainability, vol. 21, no. 2, pp. 139-154, 2019

\title{
Integrating Sustainable Development Requirements into the Secondary Stage Chemistry Curriculum in Egypt
}

\author{
Shaimaa Abdul Salam Abdul Salam Selim \\ Damietta University, Damietta, Egypt
}

\begin{abstract}
The problem of the current research lies in the need to integrate some requirements of the sustainable development (SD) in secondary school chemistry curriculum. The research specifically seeks to answer the following question: What "requirements of sustainable development" should be taught in the secondary school chemistry curriculum in Egypt? To that end, the researcher analyzed the content of chemistry curricula in the three grades of secondary education in Egypt for the school year 2017-2018, and prepared a list of $57 \mathrm{SD}$ requirements. It should be noted that fifteen requirements of sustainable development at the second-grade secondary stage were distributed into five units; the third unit included one requirement; the fourth unit comprised four requirements; and the fifth unit - one requirement. Regarding curriculum at the third-grade secondary stage, 17 requirements of sustainable development were integrated and distributed along five units.
\end{abstract}

Key words: sustainable development requirements, chemistry curriculum, secondary stage

\section{Introduction}

The present age witnesses a scientific revolution in all facets of life, particularly at the cognitive, scientific and technological levels. This revolution has led to drastic changes in life styles and patterns, resulting, in turn, in many problems that call for further study in terms of problem solving. These problems pertain to the individual environment, health, nutrition, and the society, at large. That being said, the future will witness major scientific and technological breakthroughs in fields such as scientific research, atom applications and nanotechnology.

These current changes have equally been manifested in chemistry curricula. School curricula have witnessed significant reform initiatives at both the Arab and international levels, i.e., specialized conferences and symposia in science education have been conducted; development projects have been designed for identifying the current reality of chemistry instruction and suggesting alternative solutions and prospects for future development. New advances in science have resulted in new trends in chemistry instruction that 
cope with these advances. Calls and recommendations for re-structuring chemistry curricula to meet the requirements for sustainable development (SD) have been echoed by the National Science Teacher Association (NSTA) and the American Association for the Advancement of Science (AAAS).

Chemistry plays a pivotal role in advancing humanity. Therefore, secondary school chemistry curricula should integrate SD requirements and pertinent concepts, skills, values and attitudes that could possibly qualify students for playing an active role in achieving sustainable development. It could be made possible through investment of natural and human resources. There is a need for special developmental chemistry curricula that will focus on the problems and issues of development. These curricula should also include activities through which students could possibly attain scientific facts and develop positive attitudes, values and behaviors towards their community (Matlin, Mehta, Hopf, \& Krief, 2015, p. 941).

Several studies (e.g., Juntunen \& Aksela, 2013; Kapenieks, 2016; Maude, 2014) have confirmed the importance of development as a key element for stability as well as human and social reform. Development is a continuous, comprehensive process that takes different avenues towards human luxury and well-being in line with their economic, social and intellectual needs and potential.

In the process of development, the Egyptian society faces many challenges. These include safety, stability, supplying basic life needs, power, water, transport, fuel, unifying the goals of society, achieving democracy, freedom of disseminating information, transparency, boosting production, advancing agriculture, upholding the national Egyptian identity, solving poverty, slums and illiteracy problems, supplying bread, freedom and justice among other crises sectoral and partisan facing the Egyptian society.

It has been such a challenge for curriculum designers to reconstruct school curricula to keep pace with the needs of the community. It should be noted that optimal science curricula are those whose objectives, content and methods are focused on productive learning and teaching, i.e., they are focused on teaching students functional scientific knowledge, behavior, skills and attitudes, as well as developing scientific tendencies and humanitarian values and attitudes towards the use of science and its societal applications (Deng, 2011, p. 539).

\section{Sustainable Development as a Concept}

Sustainable development is one of the important issues that attracts attention of developing countries, including Egypt. It is considered a national issue for which all efforts of the community members must be mobilized. The aim is to benefit from science and to improve the quality of life. To achieve sustainable development, more attention should be paid to all dimensions of development, including economic, social, scientific, and cultural (Salīte, 2015; Salìte et al., 2016; Salìte et al., 2018). Moreover, curricula should focus on consolidation of behavioral values so that they become common practice for learners who, in turn, become more capable of coping with new developments and challenges.

Sustainable development is a multi-dimensional process of transformation. It involves all individuals, communities, fields, governmental, non-governmental and private institutions, laws and regulations in their interactions towards coherent and integrative growth (Mechik \& Hauff, 2016, p. 110). 
There are various requirements for sustainable development, most notable among which are the following:

- Technological requirements:

The present age witnesses scientific and technological revolutions in various spheres of life that brought about change and development in the lives of individuals and communities.

- Economic requirements:

They are manifested in increasing production, reliance on domestic savings as a source of investment, development of local capacity, and fair distribution of income and wealth in society to eliminate poverty.

- Social requirements:

They are manifested in improving education, health levels and well-being of all citizens, raising interest in the middle and working class, deepening values such as love of knowledge and hard work.

- Cultural requirements:

They are manifested in raising awarness of societal thought and culture issues, consolidating values of reasoning versus rote-learning, emphasizing objectivity and openness to other cultures.

- Environmental requirements:

They are manifested in promoting the efficiency of natural resources and effective governance of these resources (e.g., water, air, energy, mineral wealth, coastal environment) and adopting sustainable production and consumption patterns (Salite et al., 2015; Biasutti, De Baz, \& Alshawa, 2016).

To achieve the SD requirements, there is a need to:

- Study all aspects of reality that call for development.

- Study optimal outcomes and distinguish among important, less important, high-priority, and temporarily impossible outcomes.

- Study possible means to achieve those outcomes and ways to overcome the difficulties.

- Manage cooperation and interaction among those interested in development.

- Prepare plans for integrative development; plans for each sector of society (Handayani, 2019, p. 45).

A few research studies have focused on integrating sustainable development requirements into curriculum. For example, Juntunen and Aksela's study (2014) aimed at using a new approach to education for sustainable development. This approach includes the following four parts: (1) Multidimensional education on sustainable development; (2) Interdisciplinary education on sustainable development; (3) Emphasizing the principles of green chemistry and (4) Responsible purchasing and sustainable consumption.

The results of Bazzanella, Friege and Lahl's study (2017) are consistent with those of Juntunen and Aksela's (2014) in that the environmental and societal benefits of sustainable chemistry include: (1) Avoiding the use of persistent, bioaccumulative and otherwise hazardous materials; (2) Using renewable resources and decreasing consumption of non-renewable resources; (3) Providing technologies that are economically competitive for and advantageous to industry. 
Sustainable curriculum would be transformative as its goal is to "equip all people with the knowledge, skills and understanding necessary to make decisions based upon their full environmental, social, cultural and economic implications" (DEWHA, 2009) rather than transmissive with a goal to provide students with knowledge. It would not be specialized, content-driven units of study on sustainability but integrated across courses and units (see Figure 1).

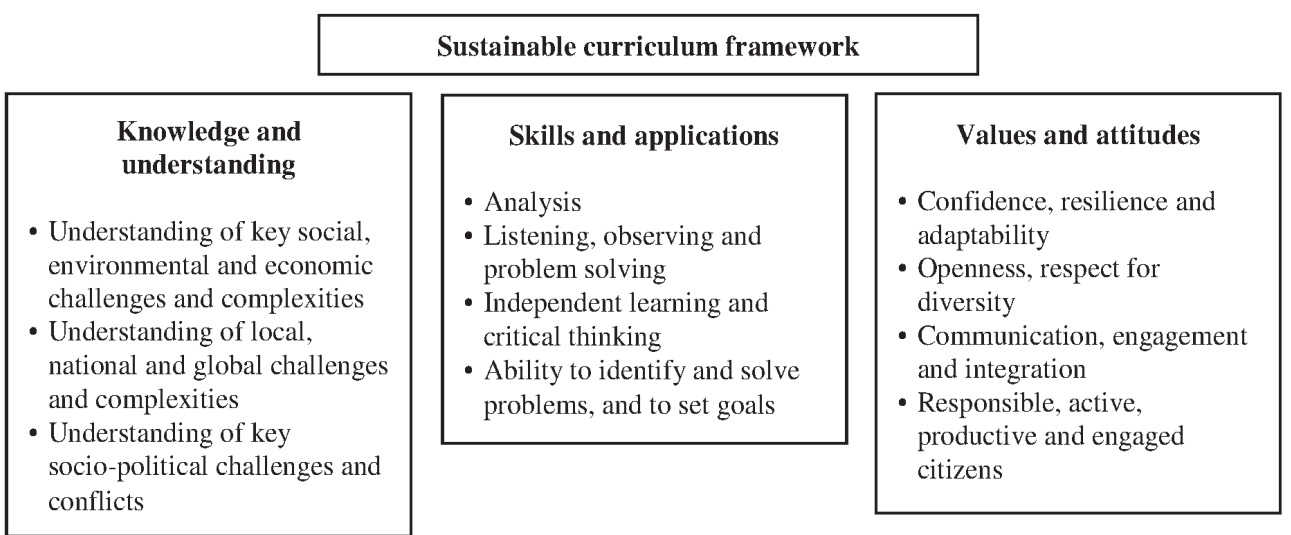

Figure 1. Sustainable curriculum framework

The following methods are used in some developed countries, such as the USA and England, to integrate the requirements of sustainable development in the secondary stage chemistry curriculum (The United Nations Educational Scientific and Cultural Organization, 2012):

- Problem analysis method

Analysis of the problem directs learners' attention to processes that can be used to analyze any issue as a series of general procedures that can be applied on a large scale, addressing environmental, social and economic problems.

- $\quad$ Storytelling

Storytelling is considered an effective educational tool to support community development, such as values derived from traditional stories and the wisdom of the elderly or inspired by stories of creatures, the matter that gives respect to the cultural heritage and environment.

- Simulation

It is done by addressing the real-life problems faced by local communities, and strengthening the link between them and the curriculum. Problems are integrated into the curriculum and learners are engaged audio-visually, emotionally and physically in educational models designed to develop their problem-solving and high order thinking skills (Žogla, 2018).

In light of rapid developments in the field of chemistry, there is an urgent need to develop chemistry curricula in ways that help develop learners' abilities to solve societal problems, make appropriate decisions, and think in a scientific way.

There is a worldwide interest in developing chemistry curricula towards optimal outcomes for individuals and society. However, chemistry still lags far beyond societal 
issues. Therefore, much criticism has been addressed to chemistry curricula in the United States and Britain for their incapacity to attract as many students as possible who could be potential scientists in the field. These points of criticism can be summed up as follows:

- The content of science textbooks hardly keeps pace with modern developments in chemistry.

- The current curricula hardly focus on providing learners with technical and technological competences derived from advanced scientific books and references and supported by the results of scientific research in all branches of science, which could possibly lead to comprehensive development of society.

- Learners are hardly made aware of chemistry as a continuous human activity that boosts their thinking and expands their vision of possible ways to make use of chemical products resulting from manipulation of different natural resources.

- Learners are hardly made aware of the importance of chemistry in the course of their life and how to deal with chemical products at home, such as canned food, cleaning supplies, pesticides and others.

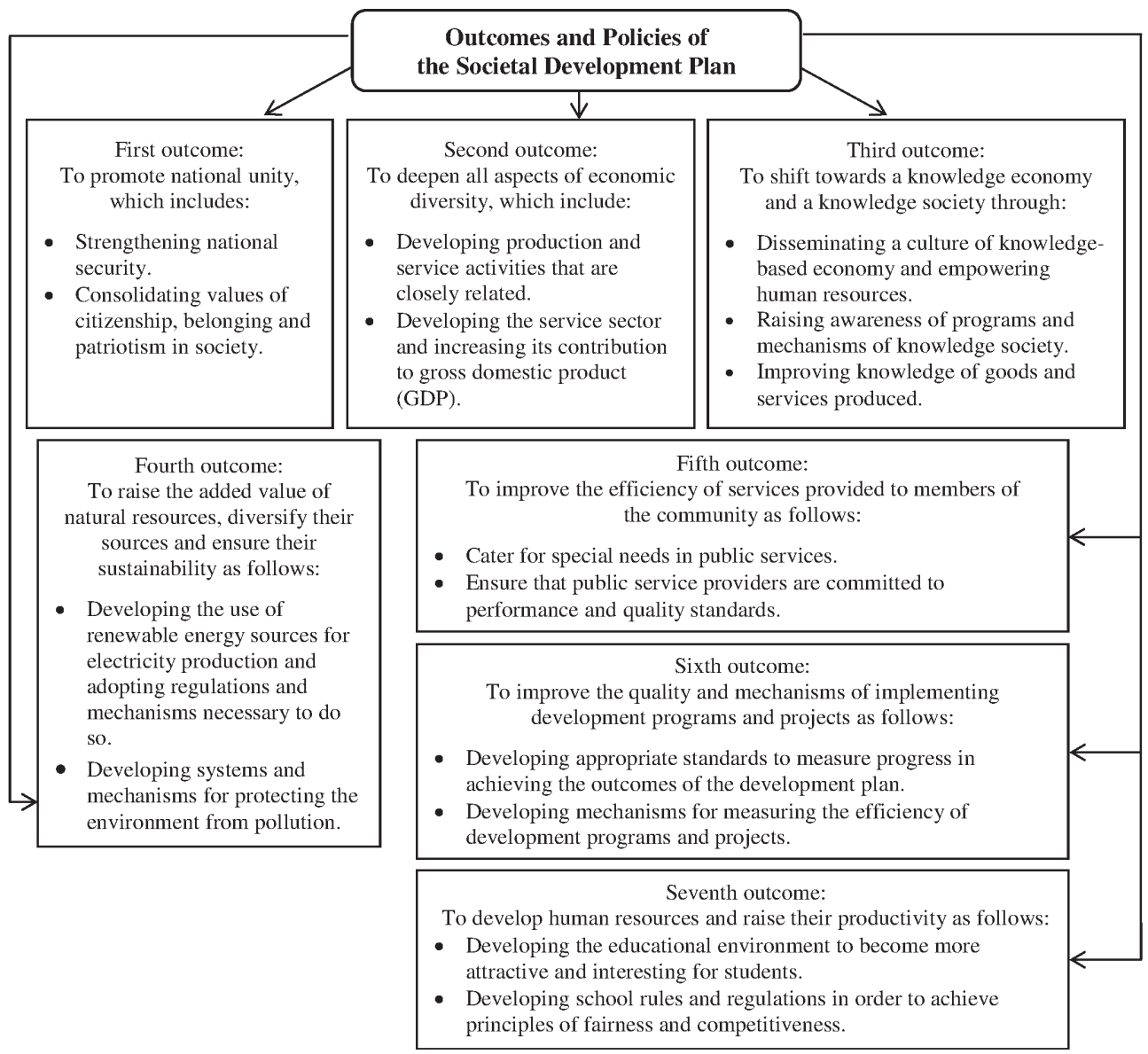

Figure 2. Outcomes and policies of the societal development plan 
In response to these critical views, chemistry curriculum development initiatives grew active worldwide. Among these initiatives was the Australian Council for Educational Research report in 2010 (Australian Academy of Science, 2016). The report echoed on the need to review secondary stage chemistry curricula in light of the outcomes and policies of the Societal Development Plan (see Figure 2).

Figure 2 shows the importance of integrating life activities in the secondary stage chemistry curriculum to help students apply and use information and to instill in them behaviors of community participation, volunteering, rationalized production and consumption, optimization of resources, resource conservation and adherence to community culture and authentic, genuine values of society.

Sustainable chemistry provides basis for evaluating and designing new chemical products and processes that minimize adverse impacts on human and environmental health. This approach, called systems thinking, is a problem-solving strategy that identifies and understands the key components of a system, in contrast to an isolated part, then investigates solutions based on the system interactions. Teaching a systems approach challenges students to apply scientific principles to solve real-world problems, demonstrates the role of chemistry as an essential science in finding solutions, and prepares future scientists for the collaborative interdisciplinary work required. Integrating sustainable chemistry into today's chemistry curriculum, as we look to the future, can be accomplished by scaffolding in these Conceptual Topics (Lyere, 2008):

- Advances in chemistry research are integral to meeting society's essential needs of food, energy, and water in a sustainable path forward.

- Chemicals and chemical products provide many benefits to society; however, unintended consequences can negatively impact humankind and the earth. Green chemistry products and technologies have shown great potential for mitigating these impacts, some of which may disproportionately affect people of low socioeconomic status.

The importance of restructuring the chemistry curriculum in a way that could support sustainable development is attributed to the following reasons:

1. It is a national need to develop a sense of belonging and identity among students at different stages of education;

2. Making community decisions must include public participation, i.e., individuals who will be affected by decisions to be taken must participate in the procedures that will lead to making these decisions;

3. Man/human is the cornerstone of environment protection and development, which are connected rather than separate (Jensz, Carroll, \& Gibson, 2005, pp. 89-94).

\section{Principles of Sustainable Chemistry}

The principles of sustainable chemistry address the reduction or removal of dangerous or harmful substances from the synthesis, production and application of chemical products and, thus, the use of substances dangerous to human health and the environment is reduced or eliminated. Eze (2015) provides a list of sustainable chemistry as follows: 1. Prevention. It is better to prevent waste than to treat or clean up waste after it is formed. 
2. Atom Economy. Synthetic methods should be designed to maximize the incorporation of all materials used in the process into the final product.

3. Designing Safer Chemicals. Chemical products should be designed to preserve efficacy of the function while reducing toxicity.

4. Less Hazardous Chemical Synthesis. Whenever practicable, synthetic methodologies should be designed to use and generate substances that possess little or no toxicity to human health and the environment.

5. Safer Solvents and Auxiliaries. The use of auxiliary substances (solvent, separation agents, etc.) should be made unnecessary whenever possible and, when used, innocuous.

6. Design for Energy Efficiency. Energy requirements should be renewable rather than depleting whenever technically and economically practical.

7. Catalysis. Catalysis reagents (as selective as possible) are superior to stoichiometric reagents.

8. Reduce Derivatives. Unnecessary derivatization (blocking group, protection/ deprotection, temporary modification of physical / chemical processes) should be avoided whenever possible.

9. Use of Renewable Feedstocks. A raw material or feedstock should be renewable rather than depleting whenever technically and economically practical.

10. Real-time Analysis for Pollution Prevention. Analytical methodologies need to be further developed to allow for real-time in-process monitoring and control prior to the formation of hazardous substances.

11. Design for Degradation. Chemical products should be designed so that at the end of their function they do not persist in the environment and instead break down into innocuous degradation products.

12. Inherently Safer Chemistry for Accident Prevention. Substance and the form of a substance used in a chemical process should be chosen so as to minimize the potential for chemical accidents, including releases, explosions, and fires.

Reviews of research dealing with sustainable chemistry across various stages of education (e.g., Belford \& Bastin, 2013; Parrish, 2014; Mahaffy, Brush, Haack, \& Ho, 2018) have revealed that sustainable chemistry is efficient chemistry. The development of benign, non-wasteful alternatives to traditional chemistry has the potential to save large amounts of money due to decreased regulation compliance as well as disposal costs. Furthermore, the basic decrease in process hazards drastically increases both worker and consumer safety. Green chemistry is necessary, responsible, interesting, efficient, and above all, it is a good chemistry.

\section{Research Problem}

Based on a review of relevant literature, there are studies that addressed the development of chemistry curricula in line with sustainable development requirements. Examples of these studies include Hill, Kumar and Verma's research (2013) that explored how chemistry and the chemical enterprise were progressing towards sustainable chemistry philosophy and practice. Jegstad and Sinnes's study (2015) offered a model of how Education for Sustainable Development (ESD) can be implemented in chemistry education. The model was developed to support chemistry teachers in their educational planning 
and included five categories: chemical content knowledge, chemistry in context, the distinctiveness and methodological character of chemistry. Moreover, Turkmen, Teksoz and Boz's study (2018) aimed at examining the role of secondary stage chemistry teachers in achieving community development.

A report issued by Nuffield Foundation in 2014 entitled "Science Education in Europe: Critical Reflections" confirmed that little attention was given in the secondary stage chemistry curriculum to the relationship between chemistry and everyday life. Conversely, scientific topics are presented as a series of steps advancing towards the scientific scene, the matter that lacks adequate examples illustrating chemistry applications in the contemporary world of secondary stage students (Osborne \& Dillon, 2014, p. 21). Moreover, recommendations of several conferences such as the International Conference on Chemistry Education (2013) stressed the need to highlight the role of the curriculum in general and chemistry curriculum in particular in making change and achieving development. Through curriculum, it is possible to achieve economic diversity, address economic and social issues, transform information into an investment, improve the quality of life and achieve the security, stability and development necessary to cope with the $21^{\text {st }}$ century challenges.

Curriculum is the cornerstone of positive and active participation in social, economic, political and cultural development. Thus, there is a need for chemistry curriculum to promote students' national identity and belonging. It should educate, train and enable students to engage actively in the development of their society.

Thus, the problem of the research lies in the need to develop high school chemistry curriculum in light of the sustainable development requirements. The present research attempts to address this problem by answering the main question: What are the requirements of sustainable development to be included in the chemistry curriculum of secondary schools in Egypt?

\section{Method}

The descriptive method was used in the research to describe and analyze pertinent literature. It was also used in drawing up the list of sustainable development requirements (SDR) to be integrated in the secondary school chemistry curriculum in Egypt.

\section{Tools and Materials}

To answer the research question, the following tools and materials were developed and used:

- A list of sustainable development requirements that should be integrated into the secondary stage chemistry curriculum.

- A questionnaire for investigating students' opinions about sustainable development requirements that should be integrated into the secondary stage chemistry curriculum. 


\section{Procedures and Results}

To answer the research question, the following steps were taken:

a) Drawing up a list of sustainable development requirements that should be integrated into the secondary stage chemistry curriculum according to the following steps:

- Sustainable development requirements that could be integrated into the secondary stage chemistry curriculum were determined in light of writings of specialized experts in sustainable development requirements (e.g., Juntunen \& Aksela, 2013; Maude, 2014).

- An initial version of the list of sustainable development requirements was drawn up, including the following:

- Fifty-seven requirements of sustainable development at the first-grade secondary stage were distributed into six units (the first unit included 32 requirements; the second unit comprised one requirement; the third unit included six requirements; the fourth unit consisted of four requirements; the fifth unit comprised four requirements; and the sixth unit - ten requirements.

- Fifteen requirements of sustainable development at the second-grade secondary stage were distributed into five units (the first unit included three requirements; the second unit comprised six requirements; the third unit consisted of one requirement; the fourth unit included four requirements; and the fifth unit - one requirement.

- Seventeen requirements of sustainable development at the third-grade secondary stage were distributed into five units (the first unit included one requirement; the second unit comprised one requirement; the third unit consisted of four requirements; the fourth unit included four requirements; and the fifth unit - seven requirements.

- Opinions of specialized jurors were investigated and they confirmed that those concepts were important and suitable to the characteristics of secondary stage students, and suggested some modifications. Thus, the total number of requirements in the final version of the list was 87 .

b) Determining the relevance of the proposed list of sustainable development requirements to be integrated into the secondary stage chemistry curriculum according to the following steps:

- The items of the list of sustainable development requirements were identified in light of opinions of a group of specialized jurors. Before each requirement three options were assigned on a Likert scale to judge how far each requirement was appropriate for the grade level (extremely suitable - fairly suitable - not suitable). The jurors were asked to express their point of view, marking $(\sqrt{ })$ before each requirement and in the Likert-scale column representing suitability of requirements for grade level.

- The relative weight of each item was calculated in order to be classified in three categories by limiting the frequencies of responses to each of the alternatives. The 'extremely suitable' option was given three points; the 'fairly suitable' option was given two points; and the 'not suitable' option was given one point. The relative weight of each requirement was calculated by multi- 
plying the number of frequencies in each option slot to the numerical value assigned to it and then adding the end result of each option slot.

- The range of each of the three ranks was calculated as follows:

- The relative weight of sustainable development requirements that ranked first ranged between 141 and 150 with a percentage of $97 \%$.

- The relative weight of sustainable development requirements that ranked second ranged between 135 and 128 with a percentage of $87.7 \%$.

- The relative weight of sustainable development requirements that ranked third ranged between 120 and 82 with a percentage of $67.4 \%$.

c) Content analysis of the secondary stage chemistry curriculum in light of sustainable development requirements:

The content of the secondary stage chemistry curriculum was analyzed in light of sustainable development requirements of the Egyptian society through the following steps: (Objective of content analysis - content analysis unit - content analysis steps checking reliability of content-analysis tool - determining content-analysis space).

1. Objective of content analysis

The content-analysis tool that the researcher developed aimed at judging the extent, the form and the level of covering of sustainable development requirements across the three grades of the secondary-stage chemistry curriculum in Egypt.

2. Content-analysis unit

The 'paragraph' unit was used for the purposes of this content analysis because it was the natural unit of meaning construction. 'Paragraph' means one or more meaningful sentences.

3. Checking reliability of content-analysis tool (sustainable development requirements) through the following steps:

- Limiting the number of paragraphs in the content of the chemistry curriculum across the three grades of the secondary stage for the school year 2017-2018.

- Using the content-analysis tool (the list of sustainable development requirements) and the paragraph unit to analyze the content of the chemistry curriculum across the three grades of the secondary stage for the school year 2017-2018.

- Re-conducting the content analysis 30 days later and applying Holsti's formula.

4. Determining the space of analysis

5. The researcher calculated the space of analysis by limiting the content of the chemistry curriculum across the three grades of the secondary stage for school year 2017/ 2018, after excluding pages that included introduction, index, figures and diagrams, maps, illustrations, summaries, questions and exercises, notes, and blank pages.

The researcher divided the pages of the curriculum content into paragraphs, each paragraph including one idea. The analysis revealed the following: The total number of paragraphs in the content of the chemistry curriculum in the first grade of the secondary stage was 616 paragraphs; the total number of paragraphs in the second grade was 494 paragraphs; and that of the third grade was 467 . The frequency of recurrent paragraphs that covered concepts pertaining to the requirements of sustainable development across the three grades of the secondary stage was calculated (see Table 1). 
Table 1

Content Analysis Results of the Secondary Stage Chemistry Curriculum in Light of Sustainable Development Requirements

\begin{tabular}{|c|c|c|c|c|c|c|}
\hline \multirow{2}{*}{$\begin{array}{l}\text { Sustainable } \\
\text { Development } \\
\text { Requirements }\end{array}$} & \multicolumn{2}{|c|}{ First-grade secondary } & \multicolumn{2}{|c|}{ Second-grade secondary } & \multicolumn{2}{|c|}{ Third-grade secondary } \\
\hline & $\begin{array}{l}\text { Number of } \\
\text { paragraphs }\end{array}$ & Percentage & $\begin{array}{l}\text { Number of } \\
\text { paragraphs }\end{array}$ & Percentage & $\begin{array}{l}\text { Number of } \\
\text { paragraphs }\end{array}$ & Percentage \\
\hline $\begin{array}{l}\text { Socio-economic } \\
\text { requirements }\end{array}$ & 15 & $2.4 \%$ & 49 & $9.9 \%$ & 12 & $2.6 \%$ \\
\hline $\begin{array}{l}\text { Environmental } \\
\text { requirements }\end{array}$ & 21 & $3.4 \%$ & - & - & 25 & $5.4 \%$ \\
\hline $\begin{array}{l}\text { Technological } \\
\text { requirements }\end{array}$ & - & - & - & - & - & - \\
\hline Total & 36 & $5.8 \%$ & 49 & $9.9 \%$ & 37 & $8 \%$ \\
\hline
\end{tabular}

Table 1 shows few recurrences of sustainable development requirements in the content of the chemistry curriculum across the three grades of the secondary stage.

d) The proposed conception of the secondary stage chemistry curriculum was developed in the form of requirements (see Table 2).

Table 2

Sustainable Development Requirements Integrated into the Secondary Stage Chemistry Curriculum

\begin{tabular}{|c|c|c|}
\hline Grade & $\begin{array}{l}\text { The unit as it } \\
\text { is in the current } \\
\text { curriculum }\end{array}$ & $\begin{array}{l}\text { Number of sustainable development requirements } \\
\text { proposed for integration }\end{array}$ \\
\hline \multirow{4}{*}{ 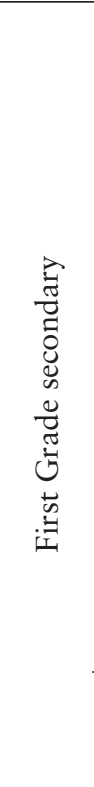 } & \multirow[t]{3}{*}{$\begin{array}{l}\text { Unit 1: } \\
\text { Chemistry - } \\
\text { Our Lives }\end{array}$} & $\begin{array}{l}20 \text { Socio-economic requirements are as follows: Alternative and inex- } \\
\text { pensive chemicals and tools - Chemical garden - Chemist skills - De- } \\
\text { veloping work skills in the chemistry lab - Home chemistry - Nano- } \\
\text { technology tools - Nano ceramic materials - Applications of nanotech- } \\
\text { nology in inorganic materials - Nanotechnology laboratory tools - } \\
\text { Social impacts of nanotechnology - Inexpensive nanoparticles - Nano- } \\
\text { technology cultural exhibition - Nanotechnology library. }\end{array}$ \\
\hline & & $\begin{array}{l}7 \text { Environmental requirements are as follows: Ways to get rid of harm- } \\
\text { ful chemicals at home - Safety precautions when handling chemicals } \\
\text { in a liquid state - Safety precautions for experiments that need heating - } \\
\text { Safety precautions when handling chemical bottles - Safety precautions } \\
\text { when handling solid chemicals - Packaging of food products with } \\
\text { nanotechnology - Construction of buildings. }\end{array}$ \\
\hline & & $\begin{array}{l}5 \text { Technological requirements are as follows: Mobile chemistry labora- } \\
\text { tory - Electronic measurement in chemistry - Chemical technology } \\
\text { specialists - Android nanoparticles - Nanotechnology applications in } \\
\text { the field of computer. }\end{array}$ \\
\hline & $\begin{array}{l}\text { Unit 2: } \\
\text { Quantum } \\
\text { Chemistry }\end{array}$ & $\begin{array}{l}1 \text { Socio-economic requirement is as follows: The role of quantum com- } \\
\text { putational chemistry in reducing pollution and toxicity in chemistry. }\end{array}$ \\
\hline
\end{tabular}


Continuation of Table 2

Unit 3: 5 Socio-economic requirements are as follows: Liquid soap industry -

Solutions - Manufacturing liquid cleaning and polishing glass - Carpet cleaning

Acids and fluid - Economic importance of sodium bicarbonate - Project for the

Bases establishment of soda.

1 Environmental requirement is as follows: Recognizing the damage caused by some acids and bases in our daily life.

\begin{tabular}{cl}
\hline Unit 4: & 4 Socio-economic requirements are as follows: Thermal insulation - \\
Thermal & Uses of thermal insulation - Manufacturing cold compresses for ball \\
Chemistry & players - Heat pumps. \\
\hline Unit 5: & $\begin{array}{l}\text { 3 Socio-economic requirements are as follows: Precautions when con- } \\
\text { Nuclear }\end{array}$ \\
ducting nuclear reactions - Nuclear submarines - Smart practices with \\
Chemistry & radioactive materials.
\end{tabular}

1 Environmental requirement is as follows: The economic importance of radioactive carbon.

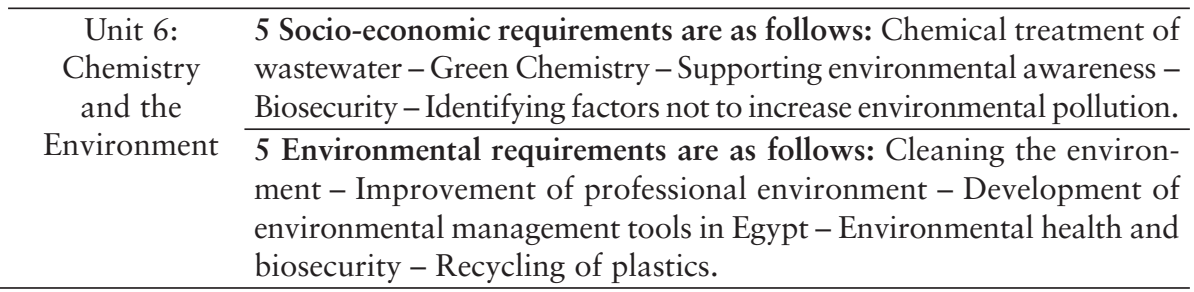

Unit 1: 3 Socio-economic requirements are as follows: The economic importance

The Structure of atomic crystals - Distinguishing between connected spectrum and

of the Atom linear spectrum - Atomic absorption spectrometer.

Unit 2: 4 Socio-economic requirements are as follows: Periodic table and classi-

Periodic Table fication of elements - The economic importance of some elements of and Classi- the periodic table - Manufacture of metal products - The economic fication of importance of non-metals.

Elements $\frac{1 \text { Environmental requirement is as follows: Recycling aluminum. }}{1 \text { Technological requirement is as follows: Electronic program of the }}$ periodic table - Using the Internet to collect periodic tables from different countries.

\begin{tabular}{cl} 
Unit 3: & 1 Technological requirement is as follows: Computer software for \\
Chemical & harmonious bond. \\
Union & \\
\hline Unit 4: & 4 Socio-economic requirements are as follows: Uses of sodium hyd- \\
Elements Re- & roxide - Uses of sodium carbonate - Fertilizer industry - The economic \\
presented in & importance of the 5A elements. \\
Some Regular & \\
Groups in the & \\
Periodic Table & \\
\hline Unit 5: & 1 Socio-economic requirement is as follows: The economic importance \\
Transitional & of the elements of the first transition chain. \\
Elements &
\end{tabular}

See next page for continuation of table 
Continuation of Table 2

\begin{tabular}{|c|c|c|}
\hline \multirow{10}{*}{ 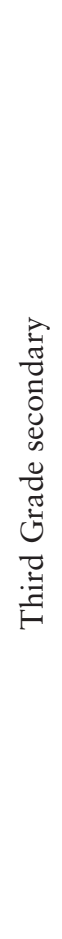 } & $\begin{array}{l}\text { Unit 1: } \\
\text { Transitional } \\
\text { Elements }\end{array}$ & $\begin{array}{l}1 \text { Socio-economic requirement is as follows: Economic importance of } \\
\text { key transitional elements - Economic importance of internal transi- } \\
\text { tional elements. }\end{array}$ \\
\hline & $\begin{array}{l}\text { Unit 2: } \\
\text { Chemical } \\
\text { Analysis }\end{array}$ & $\begin{array}{l}1 \text { Socio-economic requirement is as follows: Estimating blood sugar } \\
\text { levels. }\end{array}$ \\
\hline & \multirow{3}{*}{$\begin{array}{l}\text { Unit 3: } \\
\text { Chemical } \\
\text { Equilibrium }\end{array}$} & $\begin{array}{l}2 \text { Socio-economic requirements are as follows: Redox at home-Dif- } \\
\text { ferent metal extraction techniques used in industry. }\end{array}$ \\
\hline & & $\begin{array}{l}1 \text { Environmental requirement is as follows: Investigating the effect of } \\
\text { toxicity of some minerals on workers and the environment. }\end{array}$ \\
\hline & & $\begin{array}{l}1 \text { Technological requirement is as follows: Use of the Internet to search } \\
\text { for the most important biological interactions. }\end{array}$ \\
\hline & \multirow{3}{*}{$\begin{array}{l}\text { Unit 4: } \\
\text { Electro- } \\
\text { chemistry }\end{array}$} & $\begin{array}{l}2 \text { Socio-economic requirements are as follows: Making a battery of a } \\
\text { lemon grain - Jewelry manufacturing. }\end{array}$ \\
\hline & & $\begin{array}{l}1 \text { Environmental requirement is as follows: Methods of disposal of car } \\
\text { batteries. }\end{array}$ \\
\hline & & $\begin{array}{l}1 \text { Technological requirement is as follows: Use of the Internet to search } \\
\text { for different types of batteries at home. }\end{array}$ \\
\hline & \multirow[t]{2}{*}{$\begin{array}{l}\text { Unit 5: } \\
\text { Organic } \\
\text { Chemistry }\end{array}$} & $\begin{array}{l}4 \text { Socio-economic requirements are as follows: The importance of organic } \\
\text { chemistry in our daily lives -Making toothpaste - Extraction of energy } \\
\text { from organic waste - Perfume Chemistry. }\end{array}$ \\
\hline & & $\begin{array}{l}3 \text { Environmental requirements are as follows: The risk of burning some } \\
\text { organic materials (paper - plastic materials) - Risks resulting from the } \\
\text { chemical composition of organic materials - Recycling of organic waste. }\end{array}$ \\
\hline
\end{tabular}

It is clear from the previous examples that the sustainable development requirements are the basic requirements that train people to adopt personal lifestyles ensuring a balance between economic growth, respect for the environment and social justice. Sustainability requirements (SR), which are of a more individual nature, are identified with sustainable development requirements. They must enable human beings to face challenges such as climate change, inequality, water shortage, hunger or responsible consumption, among others, from a global perspective that favors sustainable development.

\section{Discussion of Results}

It is clear from the data analysis results that sustainable chemistry can be used to illustrate many fundamental chemistry principles throughout the curriculum. Numerous opportunities exist to include experiments and demonstrations in addition to infusing green chemistry in lessons. A sampling of illustrative examples within each sub-discipline is described below.

General chemistry. Illustrative examples include:

- Designing substances that will not involve materials harmful to the environment and their uses in products such as electronics.

- Providing students with the tools to solve problems. It means that students should be able to apply the scientific method: to define a problem clearly, to develop testable hypotheses, to design and execute experiments, to analyze data using appropriate statistical methods, and to draw appropriate conclusions. 
Quantum chemistry. Illustrative examples include:

- The role of quantum computational chemistry in reducing pollution and toxicity in chemistry.

Inorganic Chemistry. Illustrative examples include:

- Distinguishing between connected spectrum and linear spectrum.

- Classifying some metals and metalloids as critical or endangered due to geological abundance, geopolitical, and economic factors.

- Environmental impacts of ore extraction and processing.

Thermal chemistry. Illustrative examples include:

- The study of the heat energy associated with chemical reactions and/or physical transformations.

- Uses of thermal insulation, manufacturing cold compresses for ball players and heat pumps.

Organic Chemistry. Illustrative examples include:

- The importance of chemical structure and particular functional groups on the function of a molecule, its toxicity and environmental impact.

- Extraction of energy from organic waste.

\section{Recommendations}

In light of the research findings, the researcher recommends the following:

- Ensuring that science textbooks at various stages of education emphasize the importance of science and address issues relevant to everyday life so that learners appreciate the importance of science in their life.

- Re-envisioning the science curriculum in general education and developing it to keep pace with sustainability requirements in the Egyptian society, paying more attention to enrichment rather than pure achievement.

- Experimenting with the rest of the units of the proposed curriculum to avoid any shortcomings before generalization.

- Ensuring that science courses taught in teacher preparation programs at faculties of education include sustainability requirements of the Egyptian society in all aspects of daily life.

\section{Conclusion}

Curriculum is the cornerstone of positive and active participation in social, economic, political and cultural development. Thus, there is a need for chemistry curriculum to promote students' national affiliation and belonging. It should educate, train and enable students to engage actively in the development of their society. Therefore, the current study aimed to determine some requirements of sustainable development, which could be integrated into secondary stage chemistry curriculum in Egypt, and to describe how to integrate these requirements in the curriculum. To achieve these objectives, the study used the descriptive analytical method to gain access to the list of sustainable development requirements and applied the content analysis to analyze the content of chemistry textbooks. The study reached the proposed conception of the secondary stage chemistry curriculum, including sustainable development requirements. 


\section{References}

Australian Academy of Science. (2016). Chemistry for a better life. The decadal plan for Australian chemistry 2016-2025, National Committee for chemistry. Retrieved from https://www.science.org.au/files/userfiles/support/reports-and-plans/2016/ chemistry-decadal-plan-2016-25.pdf

Bazzanella, A., Friege, H., \& Lahl, B. (2017). Identification of priority topics in the field of sustainable chemistry. The Federal Ministry for the Environment. Retrieved from https://n-hoch-drei.de/wp-content/uploads/2019/03/U-72-SustainableChemistry-Priority-Topics-UBA-Texte-83-2017.pdf

Berke, R., \& Conroy, M. (2000). Are we planning for sustainable development? An evaluation of 30 comprehensive plans. Journal of the American Planning Association, 66(1), 21-33.

Belford, R., \& Bastin, L. (2013). ConfChem conference on educating the next generation: Green and sustainable chemistry - an online conference. Journal of Chemical Education, 90(4), 508-509.

Biasutti, M., De Baz, T., \& Alshawa, H. (2016). Assessing the infusion of sustainability principles into university curricula. Journal of Teacher Education for Sustainability, $18(2), 21-40$.

Deng, Z. (2011). Revisiting curriculum potential. Curriculum Inquiry, 41(5), 538-559.

DEWHA (2009). Living sustainably: The Australian Government's National Action Plan for Education for Sustainability. Australian Government, Department of the Environment, Water, Heritage and the Arts.

Eze, C. H. (2015). Enriching chemistry teacher education curriculum through integration of green chemistry principles. Knowledge Review, 32(1), Retrieved from http://www.globalacademicgroup.com/journals/knowledge\%20review/Chikwere.pdf

Handayani, M. (2019). Integrating sustainable development into higher education curriculum. Journal of Sustainable Development Education and Research, 3(1), 43-50.

Hill, J., Kumar, D., \& Verma, R. (2013). Challenges for chemical education: Engaging with green chemistry and environmental sustainability. Journal of the American Institute of Chemists, 86(1), 25-31.

Jegstad, K., \& Sinnes, A. (2015). Chemistry teaching for the future: A model for secondary chemistry education for sustainable development. International Journal of Science Education, 37(4), 655-683.

Jensz, F., Carroll, S., \& Gibson, E. (2005). Future of chemistry study supply and demand of chemists. Final Report, The Royal Australian Chemical Institute. Retrieved from https://www.raci.org.au/document/item/1782

Juntunen, M., \& Aksela, M. (2013). Life-cycle analysis and inquiry-based learning in chemistry teaching. Science Education International, 24(2), 150-166.

Juntunen, M., \& Aksela, M. (2014). Education for sustainable development in chemistrychallenge, possibilities and pedagogical models in Finland and elsewhere. Chemistry Education Research and Practice, 15(4), 488-500.

Iliško, Dz., Oḷehnoviča, E., Ostrovska, I., Akmene, V., \& Salìte, I. (2018). Meeting the challenges of ESD competency - based curriculum in a vocational school setting. Discourse and Communication for Sustainable Education, 8(2), 103-113.

Kapenieks, J. (2016). Educational action research to achieve the essential competencies of the future. Journal of Teacher Education for Sustainability, 18(1), 95-110. 
Lyere, P. (2008). Chemistry in sustainable development and global environment. Journal of chemical education, 85(12),1604-1606.

Maude, A. (2014). Sustainability in the Australian curriculum: Geography. Geographical Education, 27, 19-27.

Matlin, S., Mehta, G., Hopf, H., \& Krief, A. (2015). The role of chemistry in inventing a sustainable future. Nature Chemistry, 7(12), 941-943.

Osborne, J., \& Dillon, J. (2014). Science education in Europe see a critic. A report submitted to the Nuffield Foundation, Center of excellence for research in the development of science and mathematics education. Retrieved from ecsme.ksu.edu.sa/sites/ecsme.ks

The United Nations Educational Scientific and Cultural Organization. (2012). Education for Sustainable Development Sourcebook. UNESCO Education Sector. Retrieved from https://sustainabledevelopment.un.org/content/documents/926unesco9.pdf

Turkmen, C., Teksoz, G., \& Boz, Y. (2018). An analysis of secondary school chemistry curriculum and textbooks in terms of education for sustainable development: A case from Turkey. Conference of Australian Council for Educational Research, 12-13 August, Retrieved from https://eera-ecer.de/ecer-programmes/conference/23/network/627/

Mahaffy, P., Brush, E., Haack, J., \& Ho, F. (2018). Systems thinking, and green and sustainable chemistry. Journal of Chemical Education, 95(10), 1689-1691.

Mechik, E., \& Hauff, M. (2016). Requirements for the sustainable development of economic activities in tropical forest communities. European Journal of Sustainable Development, 5(4), 107-120.

Parrish, A. (2014). Teaching green and sustainable Chemistry: A revised one-semester course based on inspirations and challenges. Journal of Chemical Education, 91(7), 1084-1086.

Salite, I. (2008). Educational action research for sustainability: Constructing a vision for the future in teacher education. Journal of Teacher Education for Sustainability, $10(1), 5-16$.

Salìte, I., Iliško, D., \& Mičule, I. (2015). ISE action research: reorienting teachers' dispositions towards ESD, Latvia. // Kapitulčinová, D., Dlouhá, J., Ryan, A., Dlouhý, J., Barton, A., Mader, M., Tilbury, D., Mulà, I., Benayas, J., Alba, D., Mader, C., Michelsen, G., Vintar Mally, K. (Eds.), Leading Practice Publication: Professional development of university educators on Education for Sustainable Development in European countries. Prague: Charles University in Prague, pp. 105-107.

Salite, I. (2015). Searching for sustainability in teacher education and educational research: experiences from the Baltic and Black Sea Circle Consortium for educational research. Discourse and Communication for Sustainable Education, 6(1), 21-29.

Salīte, I., Drelinga, E., Iliško, Dz., Olehnoviča, E., \& Zariņa, S. (2016). Sustainability from the transdisciplinary perspective: An action research strategy for continuing Education Program Development. Journal of Teacher Educational for Sustainability, 18(2), 135-152.

Žogla, I. (2018). Science of pedagogy: Theory of educational discipline and practice. Journal of Teacher Education for Sustainability, 20(2), 31-43.

Correspondence concerning this paper should be addressed to Shaimaa Abdul Salam Abdul Salam Selim, College of Education, Damietta University, New Damietta, Postal code: 34111 - New Damietta, Egypt. Email: shaimaa1083@yahoo.com 